\title{
Práticas da Contabilidade Gerencial, Qualidade e Desempenho no Contexto de um Monopólio Natural
}

\author{
Afonso Carneiro Lima \\ https://orcid.org/0000-0001-8780-3671 | E-mail: afonsolima@unifor.br \\ Eliane Evangelista Correia \\ E-mail: eliane.e.correia@gmail.com \\ Hong Yuh Ching \\ https://orcid.org/0000-0002-3155-7261 | E-mail: hongching@fei.edu.br
}

\section{Resumo}

Objetivo: Este artigo tem como objetivo analisar a relação entre o uso de artefatos da contabilidade gerencial e porte, desempenho e qualidade dos serviços prestados por empresas brasileiras concessionárias de distribuição de energia elétrica, setor configurado como monopólio natural, marcado por um grande número de regulações e restrito a um número limitado de estratégias orientadas ao desempenho.

Método: A pesquisa envolveu 22 concessionárias de um universo de 63; utilizou-se para a análise das relações os testes não paramétricos Qui-quadrado, Kruskal-Wallis, $U$ de Mann-Whitney e $\tau$ de Kendall.

Resultados: Resultados evidenciam maior frequência da utilização dos artefatos tradicionais e sugerem uma relação entre a utilização dos artefatos e o porte da empresa. Porém, não se verificou uma relação entre a utilização desses artefatos e o desempenho nas organizações investigadas (diferenciando-se de outras pesquisas), nem com a qualidade dos serviços. Pode-se concluir que, nesse contexto de monopólio natural, informações obtidas por meio de artefatos não se prestam ao aperfeiçoamento das operações, apesar das iniciativas de um pequeno número de organizações.

Contribuições: Diversos estudos têm investigado a relação entre práticas da contabilidade gerencial (artefatos) e o desempenho organizacional em diferentes contextos, porém, pouco se sabe acerca dessa relação no contexto de setores altamente regulados.

Palavras-chave: Contabilidade gerencial. Artefatos da contabilidade gerencial. Empresas de energia elétrica. 


\section{Introdução}

O setor elétrico está configurado como um monopólio natural, isto é, sua estrutura se baseia no fato de que a maximização dos resultados e a plena eficiência no emprego dos recursos nessa atividade econômica são apenas possíveis quando ela é desempenhada em condições de exclusividade (Figueiredo, 2016). Nesse contexto, a partir da Lei $n .{ }^{\circ} 8.987$, de 13 de fevereiro de 1995, a qual trata das concessões e permissões para a prestação de serviços públicos, instituiu-se a adoção de tarifas diferenciadas, inaugurando assim uma nova fase para os serviços relacionados à distribuição de energia elétrica no País: o Estado passou a assumir o papel de regulador e fiscalizador de serviços de infraestrutura, a fim de minimizar custos e tarifas e, ao mesmo tempo, objetivando a qualidade dos serviços prestados à sociedade.

A partir dessa nova configuração institucional, a Agência Nacional de Energia Elétrica (Aneel) teria como proposta alinhar a gestão das empresas alinhada à prestação de serviços qualificados, eficientes e a preços competitivos. Assim, entre os principais aspectos do novo marco regulatório, a agência se ocupou da determinação de padrões de qualidade dos serviços de distribuição de energia, do monitoramento das operações das concessionárias e da fixação das tarifas, considerando que a fixação de um preçoteto incentivaria as concessionárias a buscarem produtividade via redução de custos (Pessanha, Souza, \& Laurencel, 2007). Para as empresas concessionárias, o desempenho financeiro tenderia a melhorar em função do aumento de eficiência operacional, de níveis mais baixos de perdas, da redução de inadimplência, do aperfeiçoamento dos sistemas de transmissão e distribuição e do acréscimo do número de consumidores regulares (Silvestre, Matos, \& Filgueira, 2010). Diante de tal cenário, argumenta-se que as práticas (ou artefatos) da contabilidade gerencial - denominação abrangente de artefatos, atividades, ferramentas, filosofias de gestão, instrumentos, métodos de custeio, modelos de gestão, métodos de avaliação ou sistemas de custeio que são empregados por profissionais da contabilidade gerencial em suas atividades (i.e., custeios por absorção, variável e padrão; valor presente e simulação; Benchmarking, Kaizen, Just in Time, etc.) (Soutes \& Guerreiro, 2007) - seriam um subsídio essencial ao processo de tomada de decisão no âmbito das concessionárias, principalmente, por possibilitar um exame detalhado acerca do desempenho das atividades, dos projetos, dos produtos e do desempenho econômico-financeiro geral (Atkinson, Kaplan, Matsumura, \& Young, 2015; Crepaldi \& Crepaldi, 2014).

Com base nos desafios de lucratividade e de crescimento das empresas distribuidoras de energia elétrica, pode-se supor a existência de uma associação direta entre o seu desempenho econômicofinanceiro (além do porte e da qualidade percebida) e o uso de artefatos, especialmente os chamados artefatos "modernos", uma vez que tais artefatos são capazes de fornecer maior fundamentação e segurança aos tomadores de decisão quanto à redução de perdas nas operações e quanto à geração de valor do que os chamados artefatos tradicionais, estes mais relacionados à determinação de custos e obtenção de informações para o controle financeiro e o planejamento.

Assim, esta pesquisa parte da seguinte pergunta: Existe uma associação entre o uso de artefatos modernos da contabilidade e o porte, a qualidade dos serviços prestados e o desempenho econômicofinanceiro nessas empresas? Objetiva-se então averiguar a relação entre a utilização desses artefatos e as variáveis "porte", "qualidade percebida" e "desempenho", no âmbito das empresas concessionárias de distribuição de energia. 
Em meio a estudos que abordam a relação entre práticas da contabilidade gerencial e o desempenho organizacional em diferentes contextos (Leite, Diehl, \& Manvailer, 2015; Gonzaga, Luz, Guimarães, \& Valerio Junior, 2010; Espejo, Portulhak, \& Martins, 2015; Klein \& Almeida, 2017; Soutes \& Guerreiro, 2007; Sulaiman, Ahmad, \& Alwi, 2004), pouco se sabe acerca dessa relação no contexto de setores altamente regulados, i.e., monopólios naturais. Além disso, ainda não há estudos que explorem como tais práticas influenciam a qualidade percebida por parte de clientes, uma medida de geração de valor sob a perspectiva da estratégia. Finalmente, esta pesquisa contribui com insights aos gestores de empresas do setor, especificamente, sobre possíveis complementariedades entre medidas financeiras e de qualidade - contribuindo assim para a verificação do impacto financeiro a partir da geração de valor - e sobre como o emprego de artefatos modernos pode auxiliar na identificação de iniciativas de baixo custo que possam contribuir para o aumento da qualidade percebida, o que pode vir a trazer retornos intangíveis via reputação.

Apresenta-se, na próxima seção, a revisão da literatura juntamente com as respectivas hipóteses; em seguida, a metodologia, com as descrições de cada variável analisada, procedimento amostral, coleta de dados e procedimentos de análise; a análise de resultados, incluindo análises complementares acerca dos dados obtidos; a conclusão, onde são enfatizadas sobretudo os achados que se configuram como contribuições teóricas, bem como sugestões para novas investigações e as referências (principalmente artigos científicos e documentos) fundamentais à pesquisa.

\section{Revisão da Literatura}

O conjunto de artefatos e a verificação do seu uso neste contexto de pesquisa baseou-se no trabalho de Soutes (2006) e no documento International Management Accounting Practice Statement (IMAP \#1): Management Accounting Concepts citado pela mesma autora (International Federation of Accountants, 1998). Adotou-se também a classificação dos artefatos em tradicionais e modernos a partir das contribuições de Sulaiman et al. (2004) e de Soutes e Guerreiro (2007); tal classificação é legitimada a partir de estudos anteriores, a exemplo de Bjoornenak e Olson (1999), mas também encontra ampla aceitação em outras pesquisas na temática verificada a partir de suas diversas citações.

Em relação à classificação, esta se dá a partir dos estágios evolutivos das práticas da contabilidade gerencial, em que são classificados em artefatos tradicionais aqueles presentes no $1^{\circ}$ e $2^{\circ}$ estágios e em artefatos modernos aqueles listados nos $3^{\circ}$ e $4^{\circ}$ estágios de evolução.

- $\quad 1^{\circ}$ estágio: artefatos voltados à determinação do custo e controle financeiro, i.e., custeio por absorção, custeio variável, custeio padrão, retorno sobre o investimento.

- $\quad 2^{\circ}$ estágio: artefatos voltados informação para controle e planejamento gerencial, i.e., preço de transferência, moeda constante, valor presente, orçamento e descentralização.

- $\quad 3^{\circ}$ estágio: artefatos voltados à redução de perdas de recursos no processo operacional, i.e., custeio baseado em atividades, custeio-alvo, Benchmarking, Kaizen, Just in Time (JIT), Teoria das Restrições, Planejamento estratégico, Gestão Baseada em Atividades (ABM).

- $\quad 4^{\circ}$ estágio: artefatos voltados à criação de valor por meio do uso efetivo dos recursos: Economic Value Added (EVA), Simulação, GECON, Balanced Scorecard, Gestão Baseada em Valor (VBM) (Soutes, 2006; International Federation of Accountants, 1998). 


\subsection{Uso de artefatos modernos e crescimento/porte da empresa}

Em relação aos estudos que abordam a relação entre o uso de artefatos modernos e porte ou crescimento organizacional, ainda não se pode verificar uma convergência significativa de resultados.

Em uma abrangente revisão da literatura sobre a prática da contabilidade gerencial em empresas da China, Índia, Malásia e Cingapura, Sulaiman et al. (2004) verificaram a utilização preponderante de artefatos tradicionais em detrimento de artefatos modernos. Embora os autores argumentem acerca da insuficiência informacional a partir de artefatos tradicionais como custeio-padrão, orçamento e ponto de equilíbrio em um contexto setorial de elevada competição, eles também reconhecem os potenciais custos de implementação dos chamados artefatos modernos na amostra, especificamente, em empresas tradicionais de manufatura atuantes em setores pouco inovadores. Assim, considerando a dinâmica competitiva como fator de estímulo ao uso de artefatos modernos, os autores chamam a atenção para a necessidade de uma conscientização acerca da existência desses artefatos, além da falta de expertise e de apoio por parte da alta gestão à sua efetiva implementação. A partir desses resultados, pode-se argumentar que o uso de artefatos modernos pode se dar de acordo com as exigências do ambiente de negócios, i.e., em setores mais dinâmicos.

O estudo de Teixeira, Gonzaga, Santos e Nossa (2011), a partir das duzentas maiores empresas do Estado do Espírito Santo e a utilização de artefatos, não evidencia uma associação significativa entre uso de artefatos modernos e porte; porém, são apresentados indícios de que a quantidade de ativos está positivamente associada a um maior número de artefatos utilizados e à intensidade dessa utilização. Tal conclusão complementa os achados de Sulaiman et al. (2004) de que o uso de artefatos modernos estaria mais relacionado ao potencial de crescimento da organização (a partir da dinâmica do setor), ao invés do porte em si.

Em uma pesquisa exploratória com nove empresas familiares de capital aberto no Brasil, Grande e Beuren (2011) buscaram identificar variações nas práticas de contabilidade gerencial a partir dos relatórios da administração no período entre 1998 e 2007. Ao longo desse período, os autores identificaram a predominância de práticas mais voltadas à determinação dos custos financeiros e controle e à redução de desperdícios, estágios 1 e 3 do relatório IMAP \#1, (International Federation of Accountants, 1998). Práticas mais relacionadas à provisão de informações para o planejamento e controle gerencial, bem como para a criação de valor mediante uso eficaz dos recursos, isto é, práticas mais complexas e mais ligadas a aspectos estratégicos, foram parcialmente verificadas, ainda que não consolidadas. A partir desse estudo, verifica-se que, mesmo em uma amostra de empresas de grande porte, a influência de normas de cunho familiar pouco importa numa estrutura organizacional profissionalizada. Além disso, dado o tamanho das empresas analisadas, não se verifica uma relação direta entre a utilização de práticas mais modernas e o crescimento, sugerindo assim não haver relação direta entre porte e o uso de práticas dessa categoria.

Já Espejo, Portulhak e Martins (2015), ao investigarem as práticas de controle gerencial em 45 hospitais universitários federais, evidenciam que em treze dos hospitais analisados há uma "baixa aderência" aos artefatos. Entre as práticas mais utilizadas, foram identificados o planejamento estratégico e análises isoladas de receitas, custos e despesas, centros de custos e grupos de serviço. Práticas mais avançadas foram identificadas em apenas dois dos hospitais de grande porte. Assim, mesmo considerando diferentes amostras de empresas em setores distintos, pode-se verificar que tais resultados corroboram os desdobramentos apontados em Grande e Beuren (2011).

Por meio de uma abordagem do ciclo de vida da organização, Paulo e Cintra (2018) verificaram como o uso dessas práticas se altera ao longo do ciclo de vida de uma empresa em um setor marcado por forte dinâmica competitiva, identificando que a empresa, a cada ciclo de vida, utilizou-se de artefatos gerenciais como subsídio ao seu crescimento, porém de maneira reativa e ad hoc, isto é, como resposta a problemas que emergiram com o crescimento da empresa e a complexidade das operações. Tais resultados ilustram uma relação parcial entre porte/crescimento e o uso de artefatos modernos. 
As contribuições ora apresentadas permitem concluir que ainda não há uma relação claramente direta entre o porte organizacional e a utilização de artefatos modernos da contabilidade gerencial, porém, trazem à luz a questão da dinâmica competitiva e a complexidade dos problemas e questões vivenciada a partir do crescimento como fatores que certamente influenciam a utilização de artefatos modernos. Considerando os limites de atuação das empresas distribuidoras a partir do novo marco regulatório, i.e., delimitação das tarifas, exigência de padrões de qualidade, pode-se inferir que a utilização de artefatos modernos é muito mais preponderante para as estratégias de crescimento dessas empresas. Assim, a seguinte hipótese pode ser derivada para a pesquisa em questão:

H1: Há uma associação positiva entre a utilização de artefatos modernos da contabilidade gerencial e o porte nas empresas concessionárias de energia elétrica.

\subsection{Uso de artefatos modernos e desempenho da empresa}

Em se tratando da relação entre a utilização de artefatos modernos nas empresas e desempenho organizacional, Ittner e Larcker (1995) ressaltam que não se pode vincular o uso de práticas da contabilidade a uma vantagem competitiva, isto é, a um desempenho superior em relação aos seus competidores. Em estudo posterior (Ittner \& Larcker, 1997), os autores evidenciaram, a partir de uma amostra de empresas de diferentes países que o desempenho obtido a partir de práticas da contabilidade ou de mecanismos de controle estratégico variam de setor para setor; ao argumentarem a necessidade de respostas criativas e flexíveis por parte das empresas, os autores ainda mostraram que em diversos contextos, a utilização de controles estratégicos pode reduzir o desempenho da empresa.

No Brasil, o estudo de Soutes e Guerreiro (2007), similarmente, apontou que empresas que utilizavam artefatos modernos também apresentavam índices de desempenho diferenciado. Porém, não foram identificadas relações entre o uso dos artefatos e variáveis como porte, setor de atuação e controle acionário. Em outra amostra de empresas, Guerreiro e Soutes (2013), analisando a relação entre técnicas de gestão baseadas no tempo (Time-Based Management) e o desempenho organizacional, não identificaram uma associação entre o uso dessas técnicas mais complexas e o retorno sobre os ativos, indicador-chave de produtividade. Tal resultado leva a crer que, apesar da utilização de tais práticas, haja restrições ou gargalos fora do ambiente organizacional.

Já Gonzaga, Luz, Guimarães e Valerio Júnior (2010), ao relacionarem o porte das empresas e a utilização de artefatos (i.e., benchmarking, orçamento, Balanced Scorecard, custeio padrão, planejamento estratégico, custeio por absorção, preço de transferência e custeio variável) evidenciaram uma relação positiva entre a quantidade e a intensidade de uso dos artefatos e o valor dos ativos das empresas, isto é, foi identificada uma relação direta entre a utilização dos artefatos e o desempenho.

Em estudo em Minas Gerais com 68 cooperativas agropecuárias, Reis e Teixeira (2013) verificaram que 19 delas, as quais utilizavam artefatos modernos, apresentaram respectivamente faturamentos e ativos médios da ordem de 2 a 3,4 vezes maior do que aquelas cujo uso se dava a partir de artefatos mais tradicionais; esses resultados levam a crer que a utilização de artefatos modernos contribuem para o desempenho organizacional, muito embora as razões e aspectos subjacentes necessitem ser mais bem investigados. Nessa mesma linha, Morais, Coelho e Holanda (2014), ao examinarem a associação entre o uso de artefatos e o objetivo de maximização do valor em empresas de capital aberto do Brasil, ilustram que a quantidade de artefatos implementados não contribui para a maximização do desempenho da empresa, mas, sim, para a sua modernização contínua. Com isso, cabe uma discussão mais detalhada sobre essa relação, envolvendo o contexto de análise desses artefatos, a velocidade de implementação efetiva (e institucionalização desses artefatos), bem como os principais fatores que influenciam a sua implementação tendo em vista o contexto competitivo. 
A partir dos estudos supracitados, ainda não se pode verificar uma relação clara entre o uso de artefatos modernos e desempenho, fato que leva à necessidade de maiores verificações, além de uma maior consideração do contexto competitivo. Neste caso, devido a limitações regulatórias de relativas a tarifas e padrões de qualidade exigidos às empresas distribuidoras de energia, pode-se argumentar que estas podem aumentar seu desempenho a partir do uso de práticas modernas da contabilidade gerencial, em especial por meio de decisões que impactem em eficiência operacional e financeira. Assim, estabeleceu-se a seguinte hipótese:

H2: Há uma relação positiva entre a utilização de artefatos modernos da contabilidade gerencial e o desempenho econômico-financeiro das empresas concessionárias de energia elétrica.

\subsection{Uso de artefatos modernos e qualidade}

Apesar da relação de complementariedade entre a gestão da qualidade e contabilidade gerencial, considerando seus efeitos no desempenho das empresas (Sedevich-Fons, 2018), de maneira geral, não foram identificados estudos tratando da relação entre a utilização de artefatos modernos da contabilidade por empresas e a percepção de qualidade a partir de produtos e serviços. Contudo, alguns estudos identificados nessa linha serviram como apoio para fundamentar a relação entre o uso de artefatos e a qualidade percebida, isto é, a avaliação da qualidade de produtos e serviços pelo cliente final.

Um dos primeiros estudos relacionando práticas da contabilidade gerencial e qualidade é também o de Ittner e Larcker (1995), que, por meio de pesquisas extensivas com empresas dos setores automotivo e de informática, evidenciaram que a qualidade, enquanto filosofia de gestão, está diretamente associada ao subsídio informacional de modernas práticas da contabilidade gerencial. Da mesma forma, Ittner e Larcker (1997) mostraram a partir de uma amostra de empresas de diferentes países a relevância do suporte informacional da contabilidade às ações de gestão focadas em qualidade e que tais informações ou controles necessários variam entre os setores.

Mais recentemente, em pesquisa realizada no contexto brasileiro, especificamente no setor hoteleiro, Lunkes et al. (2018) apontaram uma tendência de utilização de medidas não financeiras, mais voltadas à inovação e à gestão baseada em atividades, apesar do predomínio do uso de práticas tradicionais da contabilidade gerencial. Considerando o contexto operacional do setor hoteleiro, marcado pela sazonalidade, volatilidade da demanda, perecibilidade, tempo reduzido de serviço, elevados níveis de investimento em ativos fixos e de custos fixos, além de diversidade e intensidade da mão de obra, pode-se concluir que a qualidade é uma medida-chave para nortear e avaliar a multiplicidade das operações como meio de diferenciação ou fidelização. Tal aspecto ilustra uma inclinação natural à adoção de práticas da contabilidade aderentes à necessidade de clientes, visto que são poucas as possíveis estratégias para aumento de receitas, em detrimento de estratégias de otimização. Pode-se extrapolar essa mesma lógica para setores como o energético, em que a fixação de limites de preço (Pessanha et al., 2007) acaba por limitar as estratégias para o aumento de receitas. Assim, partindo-se do pressuposto de que as empresas do setor energético tenderiam a utilizar subsídios informacionais por meio de artefatos modernos para garantir melhores controles e ações de qualidade em seus serviços em consonância aos padrões regulatórios, sugere-se a seguinte hipótese:

H3: Há uma relação positiva entre a utilização de artefatos modernos da contabilidade gerencial e a qualidade percebida pelo consumidor em relação aos serviços prestados por empresas concessionárias de energia elétrica.

Apoiando-se nesta revisão da literatura, a próxima seção apresenta os aspectos metodológicos da pesquisa, incluindo descrições quanto à abordagem, descrição e processo de coleta de dados e procedimentos analíticos. 


\section{Metodologia}

Considerando o objetivo desta pesquisa, adotou-se uma abordagem quantitativa, utilizando-se tanto dados secundários quanto primários. Os dados secundários foram compostos por documentos setoriais obtidos nas páginas eletrônicas da Agência Nacional de Energia Elétrica (Aneel), da Associação Brasileira de Distribuidores de Energia Elétrica (Abradee) e em relatórios publicados nas páginas eletrônicas das empresas concessionárias; já os dados primários foram obtidos por meio de um questionário enviado a profissionais ligados às áreas contábil ou administrativo-financeira com conhecimento das rotinas e práticas da contabilidade gerencial das respectivas empresas em que atuam.

Em relação à amostra, cabe ressaltar que o Brasil possui 101 distribuidoras de energia elétrica, sendo 63 delas concessionárias e 38 permissionárias, além de treze cooperativas de eletrização rural cuja operação é regida por autorização precária e em processo de regularização para se tornarem concessionárias ou permissionárias (Aneel, 2016a). Inicialmente, foram contempladas as 101 distribuidoras, porém, devido ao baixo índice de respostas, optou-se por trabalhar com as 63 concessionárias. Destas, $73 \%$ são de capital privado. Quanto ao porte, $59 \%$ são de grande porte ( $>1 \mathrm{TWh}$ ) e $41 \%$ de pequeno porte. Assim, considerou-se para fins de procedimento uma amostragem não probabilística, situação em que há uma escolha deliberada de seus elementos, mas cujos resultados não são representativos da população (Fonseca \& Martins, 2012). Seguindo essa linha de raciocínio, adotou-se a técnica de amostragem por quotas, tendo em vista a manutenção da proporcionalidade de características fundamentais na amostra final presentes na população (Curwin \& Slater, 2007; Cochran, 2007). A amostragem por quotas consiste em uma amostra deliberadamente selecionada com base no julgamento do(a) pesquisador(a), restrita a dois estágios: a geração de categorias ou quotas de controle de elementos da população e a seleção dos elementos da amostra, com base em conveniência ou julgamento (Malhotra, 2012). Foram selecionadas, assim, 22 concessionárias de um universo de 63 empresas (35\% da população), observando-se os seus portes (pequena ou grande) e a origem do capital (público ou privado), conforme a Tabela 1.

Tabela 1

Dimensões do universo e da amostra da pesquisa

\begin{tabular}{|c|c|c|c|c|c|c|c|c|}
\hline \multirow{2}{*}{ Porte } & \multicolumn{4}{|c|}{ Privado } & \multicolumn{4}{|c|}{ Público } \\
\hline & Universo & $\%$ & Amostra & $\%$ & Universo & $\%$ & Amostra & $\%$ \\
\hline Grande & 25 & $54 \%$ & 8 & $53 \%$ & 12 & $71 \%$ & 5 & $71 \%$ \\
\hline Pequeno & 21 & $46 \%$ & 7 & $47 \%$ & 5 & $29 \%$ & 2 & $29 \%$ \\
\hline Total & 46 & $100 \%$ & 15 & $100 \%$ & 17 & $100 \%$ & 7 & $100 \%$ \\
\hline
\end{tabular}

Em relação ao perfil dos sujeitos, cabe ressaltar que três deles respondem, cada um, por duas empresas. Assim, têm-se 19 respondentes, dos quais 16 atuam na área contábil e os demais junto a áreas de planejamento e/ou controle. Treze deles trabalham há mais de dez anos na empresa atual, e o tempo médio de experiência verificado após obtenção do diploma de graduação foi de 12 anos. Quanto ao grau de conhecimento sobre os artefatos, $73 \%$ deles afirmaram possuir conhecimento e $27 \%$ afirmaram ter pouco conhecimento sobre os artefatos. Apenas o respondente da concessionária CPFL afirmou ter conhecimento aprofundado sobre o assunto. Uma breve caracterização dos respondentes pode ser visualizada na Tabela 2. 
Tabela 2

Perfil dos sujeitos da pesquisa

\begin{tabular}{|c|c|c|c|c|}
\hline Respondente & Concessionária & Cargo & Formação & $\begin{array}{c}\text { Atuação na } \\
\text { empresa (anos) }\end{array}$ \\
\hline \multirow{2}{*}{1} & COELCE & \multirow{2}{*}{$\begin{array}{l}\text { Gerente de Planejamento e } \\
\text { Controle }\end{array}$} & \multirow{2}{*}{ Ciências Contábeis } & \multirow{2}{*}{2} \\
\hline & AMPLA & & & \\
\hline 2 & CELG Distribuição S/A & $\begin{array}{c}\text { Superintendente de Planejamento } \\
\text { Econômico-Financeiro }\end{array}$ & Ciências Econômicas & 13 \\
\hline 3 & CEMIG & Superintendente de Controladoria & Ciências Contábeis & 30 \\
\hline 4 & COPEL & Gerente Contábil & Ciências Contábeis & 13 \\
\hline 5 & LIGHT & Gerente Contábil & Ciências Contábeis & 7 \\
\hline 6 & CEEE D & Contador(a) & Ciências Contábeis & 11 \\
\hline \multirow{2}{*}{7} & CEMAR & \multirow{2}{*}{ Coordenador(a) de Orçamento } & \multirow{2}{*}{ Ciências Contábeis } & \multirow{2}{*}{1} \\
\hline & CELPA & & & \\
\hline 8 & CEB Distribuiç̧ão & Contador(a) & Ciências Contábeis & 6 \\
\hline 9 & ELETROCAR & Gerente Contábil & Ciências Contábeis & 37 \\
\hline \multirow[t]{2}{*}{10} & BANDEIRANTE & \multirow{2}{*}{ Gerente Contábil } & \multirow{2}{*}{ Ciências Contábeis } & \multirow{2}{*}{9} \\
\hline & ESCELSA & & & \\
\hline 11 & $\begin{array}{l}\text { Muxfeldt, Marin e Cia. } \\
\text { Ltda. }\end{array}$ & Supervisor(a) Contábil & Ciências Contábeis & 20 \\
\hline 12 & $\begin{array}{l}\text { Força e Luz Coronel } \\
\text { Vivida Ltda. }\end{array}$ & Assessor(a) Administrativo(a) & Administração & 30 \\
\hline 13 & CHESP & $\begin{array}{l}\text { Gerente do Departamento de } \\
\text { Contabilidade }\end{array}$ & Ciências Contábeis & 40 \\
\hline 14 & $\begin{array}{l}\text { Nova Palma Energia } \\
\text { Ltda. }\end{array}$ & Contador(a) & Ciências Contábeis & 2 \\
\hline 15 & DME Distribuição S/A & Gerente Contábil & Ciências Contábeis & 27 \\
\hline 16 & $\begin{array}{l}\text { Iguaçu Distribuidora de } \\
\text { Energia Elétrica Ltda. }\end{array}$ & Contador(a) & Ciências Contábeis & 30 \\
\hline 17 & COCEL & Contador(a) & Ciências Contábeis & 16 \\
\hline 18 & $\begin{array}{l}\text { Hidroelétrica Panambi } \\
\text { S/A }\end{array}$ & Supervisor(a) de Contabilidade & Ciências Contábeis & 15 \\
\hline 19 & CPFL Energia & Coordenador(a) de Contabilidade & Ciências Contábeis & 19 \\
\hline
\end{tabular}

O questionário, elaborado a partir da relação de artefatos apresentada em Soutes (2006), teve a finalidade de levantar informações sobre o conhecimento e a utilização dos artefatos pelas empresas. Sua aplicação se deu ao longo do segundo semestre de 2017.

Conjugando os dados primários e secundários para análise, a Tabela 3, a seguir, descreve as respectivas fontes de dados, variáveis de análise bem como seu detalhamento. 
Tabela 3

Variáveis utilizadas na pesquisa

\begin{tabular}{|c|c|c|}
\hline Variáveis & Especificação das Variáveis & Fonte \\
\hline $\begin{array}{l}\text { Artefatos da } \\
\text { contabilidade }\end{array}$ & $\begin{array}{l}\text { Atividades, ferramentas, instrumentos, filosofias e modelos de } \\
\text { gestão utilizados por profissionais da contabilidade gerencial, no } \\
\text { exercício de suas funções (Soutes, 2006). }\end{array}$ & $\begin{array}{l}\text { Dados obtidos a partir de } \\
\text { questionário fundamentado } \\
\text { em Soutes (2006) e } \\
\text { International Federation of } \\
\text { Accountants (1998) }\end{array}$ \\
\hline \multirow{2}{*}{ Desempenho } & Eficiência $=\frac{P M S O_{A^{2}}}{P M S O_{R^{3}}}-1$ & $\begin{array}{l}\text { ANEEL (2016a; 2016b; } \\
\text { 2017) }\end{array}$ \\
\hline & Rentabilidade $=\frac{E B I T_{A^{4}}-E B I T_{R^{5}}}{B R L^{6}}$ & $\begin{array}{l}\text { ANEEL (2016a; 2016b; } \\
\text { 2017) }\end{array}$ \\
\hline
\end{tabular}

Indicador de Desempenho Global de Continuidade (DGC): Examina

o nível da continuidade do serviço prestado pela distribuidora

em relação aos limites estabelecidos pela ANEEL para a sua área de concessão e, em comparação às demais distribuidoras. Para o

ANEEL (2013; 2016a;

cálculo, consideram-se os seguintes indicadores: $D E C^{7}$ e $F E C^{8}$.

Índice Aneel de Indicador de satisfação do consumidor residencial quanto aos serviços

Satisfação do prestados, compondo-se em cinco variáveis: qualidade percebida, valor

Consumidor (lasc) percebido, satisfação global, confiança no fornecedor e fidelidade.

Porte da São consideradas de grande porte quando a empresa tem

concessionária

faturamento superior a 1 TWh (terawatt hora) e, de menor porte, quando menor ou igual a 1 TWh.

Origem do capital o controle acionário pode ser público ou privado. ABDEE

Nota: 'Optou-se por uma relação não atualizada desses artefatos tendo em vista a possibilidade de comparação dos resultados com os de outros estudos que se utilizaram do inventário baseado em Soutes (2006), a partir do IFAC (1998).

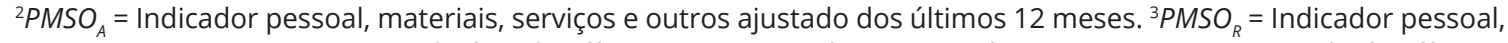
materiais, serviços e outros regulatório dos últimos 12. ${ }^{4} E B I T_{A}=$ lucro antes de juros e impostos ajustado dos últimos 12 meses. ${ }^{5} E B I T_{R}=$ lucro antes de juros e impostos regulado dos últimos 12 meses ajustado. ${ }^{6} B R L=$ Base de remuneração líquida. ${ }^{7} D E C$ = Duração Equivalente de Interrupção por Unidade Consumidora: número de horas que um consumidor permanece sem energia elétrica durante determinado período. ${ }^{8} \mathrm{FEC}=$ Frequência Equivalente de Interrupção por Unidade Consumidora: identifica quantas vezes, em média, houve interrupção, na unidade consumidora.

Em relação às medidas de desempenho específicas ao setor, a rentabilidade é obtida pelo quociente da diferença entre o lucro operacional (Ebit) realizado e o lucro operacional regulatório (realizado menos regulatório) pela base de remuneração líquida (montante de investimentos efetivados pelas empresas na prestação dos serviços a ser coberto pelas tarifas cobradas aos consumidores). Assim, quanto maior o índice, mais rentável é a empresa. Eficiência, por sua vez, obtém-se por meio do quociente entre a eficiência das despesas com pessoal, material, serviços e outros (PMSO realizado) e o PMSO regulatório, patamar considerado como benchmark para as empresas distribuidoras de energia. Dessa forma, quanto maior o valor obtido a partir desse quociente, menor é a eficiência na gestão de custos por parte da empresa. Já o indicador Desempenho Global de Continuidade, indicador de natureza operacional, é calculado por meio da média aritmética simples das razões entre valores realizados e limites regulatórios anuais dos indicadores Duração Equivalente de Interrupção por Consumidora (DEC) e Frequência Equivalente de Interrupção por unidade Consumidora (FEC). Assim, índices DGC inferiores a 1 são desejáveis, visto que este se trata de um limite regulatório para interrupções na transmissão de energia. 
A qualidade percebida dos serviços de distribuição de energia é mensurada por um indicador geral de satisfação do consumidor residencial composto de cinco variáveis: qualidade percebida, valor percebido, satisfação global, confiança no fornecedor e fidelidade. Qualidade percebida compõe-se de 17 itens agrupados em 3 dimensões: informações ao cliente, acesso à empresa e confiabilidade nos serviços; valor percebido avalia a percepção do consumidor na dimensão econômica (3 itens); satisfação global, satisfação ampla relativa à empresa e a distância entre a empresa em análise e uma empresa percebida como ideal (3 itens); confiança no fornecedor a partir da visão do consumidor (4 itens) e fidelidade, mensurada a partir da averiguação de intenção de troca (3 itens). Cada uma dessas cinco variáveis se utiliza de uma escala de avaliação distinta e cada indicador obtido mediante modelagem via Partial Least Squares (PLS) e, em seguida, ponderados no índice Aneel de satisfação do consumidor (Iasc). A coleta de dados para a composição desses indicadores se dá anualmente mediante entrevistas junto a domicílios sorteados aleatoriamente.

Para a análise estatística das hipóteses, foram utilizados os testes não paramétricos destacados na Tabela 4.

Tabela 4

Testes utilizados para tratamentos das hipóteses

\begin{tabular}{clc}
\hline H1 & $\begin{array}{l}\text { Tá uma associação positiva entre a utilização de artefatos modernos da } \\
\text { contabilidade gerencial e o porte nas empresas concessionárias de energia elétrica. }\end{array}$ & teste Qui-Quadrado ( $\chi^{2}$ ) \\
\hline H2 & $\begin{array}{l}\text { Há uma relação positiva entre a utilização de artefatos modernos da contabilidade } \\
\text { gerencial e o desempenho econômico-financeiro das empresas concessionárias de }\end{array}$ & teste Mann-Whitney (U) \\
\hline H3 & $\begin{array}{l}\text { Há uma relação positiva entre a utilização de artefatos modernos da contabilidade } \\
\text { gerencial e a qualidade percebida pelo consumidor em relação aos serviços }\end{array}$ & teste Mann-Whitney (U) \\
\hline
\end{tabular}

Testes não paramétricos são aplicáveis à análise de pequenas amostras $(\mathrm{n}<30)$ e não dependem de parâmetros populacionais, tais como média, variância, desvio padrão etc., derivados de suas respectivas estimativas amostrais (Fonseca \& Martins, 2012; Bruni, 2012). Para se obter perfis de grupos entre as variáveis associadas, utilizou-se o teste de Kendall (Field, 2009). As análises foram realizadas por meio do software IBM Statistics Package for the Social Sciences (SPSS) versão 18.

A seção seguinte traz a análise dos dados a partir do levantamento documental e de um questionário nas áreas de planejamento e de controladoria das empresas de energia. 


\section{Análise dos Resultados}

A partir de uma análise descritiva inicial referente à utilização dos artefatos da contabilidade gerencial na amostra selecionada, verificou-se, dentre os artefatos modernos, o predomínio do planejamento estratégico (19 empresas), do benchmarking (18 empresas) e do Balanced Scorecard (19 empresas); quanto à utilização dos artefatos tradicionais, estes mais empregados que os modernos, sobressaem-se o orçamento (20 empresas), o custeio variável (18 empresas), o retorno sobre o investimento (16 empresas) e a gestão baseada em valor (VBM) (15 empresas); já os artefatos menos utilizados, dos quais todos estão classificados como modernos, têm-se: kaizen (2 empresas), Gecon (2 empresas) e Just in Time (3 empresas). Percebe-se a predominância do uso dos artefatos tradicionais em relação aos modernos, visto que 16 empresas ( $73 \%$ da amostra) utilizam majoritariamente artefatos tradicionais, divergindo de resultados como os de Soutes e Guerreiro (2007), em que 66\% das empresas em análise utilizavam artefatos modernos. Este é um achado relevante, pois, supondo-se que a influência regulatória descrita por Pessanha et al. (2007) e Silvestre et al. (2010) exigisse o uso de artefatos modernos, mais direcionados à redução de perdas de recursos no processo operacional e à geração de valor por meio das operações (Soutes, 2006; International Federation of Accountants, 1998), esperava-se que a maioria das empresas investigadas fizesse uso desses artefatos ao invés daqueles mais tradicionais. Além disso, as variáveis previamente definidas para o estudo estão mais diretamente associadas ao propósito dos chamados artefatos modernos.

Ao se averiguar o conhecimento dos respondentes acerca dos artefatos da contabilidade gerencial, observou-se que $73 \%$ deles possui conhecimento; os demais respondentes ou revelaram ter pouco conhecimento ou desconhecem.

Em relação à confiabilidade das respostas pertinentes à utilização dos artefatos, identificada pelo teste do alfa de Cronbach, obteve-se o valor de 0,9 , indicando assim um nível de excelência para a realização de inferências estatísticas, apresentando-se um percentual de $90 \%$, superior ao que, em geral, é aceito, isto é, 0,7 (HAIR et al., 2009).

\subsection{Utilização de artefatos modernos e porte da empresa}

Para se testar a hipótese H1, empregou-se o teste Qui-Quadrado $\left(\chi^{2}\right)$, objetivando detectar a existência de associação significativa entre duas variáveis categóricas (Field, 2009). Sendo os valores $\chi^{2}$ da tabela de valores críticos dependentes do nível de significância adotado e do número de graus de liberdade, utilizou-se o nível de significância (a) de 5\%. Para fins de análise, restringiram-se as respostas favoráveis ao uso de artefatos modernos às notas 4 e 5 a partir de uma escala de 1 a 5 (Tabela 5).

Tabela 5

Cálculo da contingência e teste Qui-quadrado de associação entre uso de artefatos modernos e o porte da empresa

\begin{tabular}{lccccc}
\hline \multirow{2}{*}{ Porte } & \multicolumn{2}{c}{ Sim (notas 4 e 5) } & \multicolumn{2}{c}{ Não (notas 1, 2 e 3) } & \multirow{2}{*}{ Total } \\
\cline { 2 - 5 } & Respostas & Qui-Quadrado & Respostas & Qui-Quadrado & \\
\hline Grande & 90 & 1,85 & 79 & 1,58 & \\
\hline Pequeno & 42 & 2,67 & 154 & - & 2,29 \\
\hline Total & 132 & - & & 79 & 286 \\
\hline
\end{tabular}


Nota-se que para $\chi_{(0.05-1)}^{2}$ os valores críticos são iguais a 3,84. Como o valor calculado supera o valor crítico $(8,38>3,84)$ ao nível de significância $(\alpha)$ de $5 \%$, pode-se afirmar que o porte da empresa possui associação significativa à utilização de artefatos modernos. Comparativamente, nos resultados obtidos por Gonzaga et al. (2010), as empresas de grande porte estão positivamente associadas a uma maior quantidade e intensidade de uso dos artefatos, embora os autores não tivessem analisado os estágios dos artefatos.

\subsection{Utilização de artefatos modernos e desempenho}

Para se testar $\mathrm{H} 2$, foram consideradas as análises cruzadas de indicadores financeiros, referentes ao ano de 2016 (eficiência, rentabilidade e DGC) com a utilização ou não de artefatos modernos pelas empresas. Para a devida avaliação, adotou-se a seguinte regra: nota 1 (sim), caso a resposta média quanto ao uso de artefatos modernos for maior do que 3, e 0 (não), caso contrário. Para testar essa hipótese, utilizou-se o teste Mann-Whitney ( $U$ ). De acordo com Bruni (2012), este teste é a versão não paramétrica equivalente ao teste paramétrico $t$ (Student), devendo ser empregado na análise sobre duas amostras, independentemente de terem sido extraídas a partir de médias iguais. Os valores de $U$, calculados a partir do referido teste, avaliam o grau de entrelaçamento dos dados dos dois grupos após a ordenação.

O teste valor-p indica a probabilidade de ocorrência dos valores da estatística mais extremos do que o observado, sob a premissa de a hipótese nula ser verdadeira. Para examinar a hipótese nula contra a hipótese alternativa, empregou-se a escala de evidência, sugerida por Fisher, em que se rejeita esta hipótese nula para os casos em que os valores do valor-p sejam menores do que 0,05 (Morettin, 2009).

\subsubsection{Indicador de eficiência}

Ao se comparar estatisticamente as variáveis artefatos modernos e indicador de eficiência, observouse que o resultado obtido para o valor-p foi superior ao nível de significância $(0,8212>0,05$ com $U=56)$, concluindo-se não haver diferenças significativas entre os valores do indicador de eficiência e as empresas que usam, ou não, artefatos modernos (Figura 1).

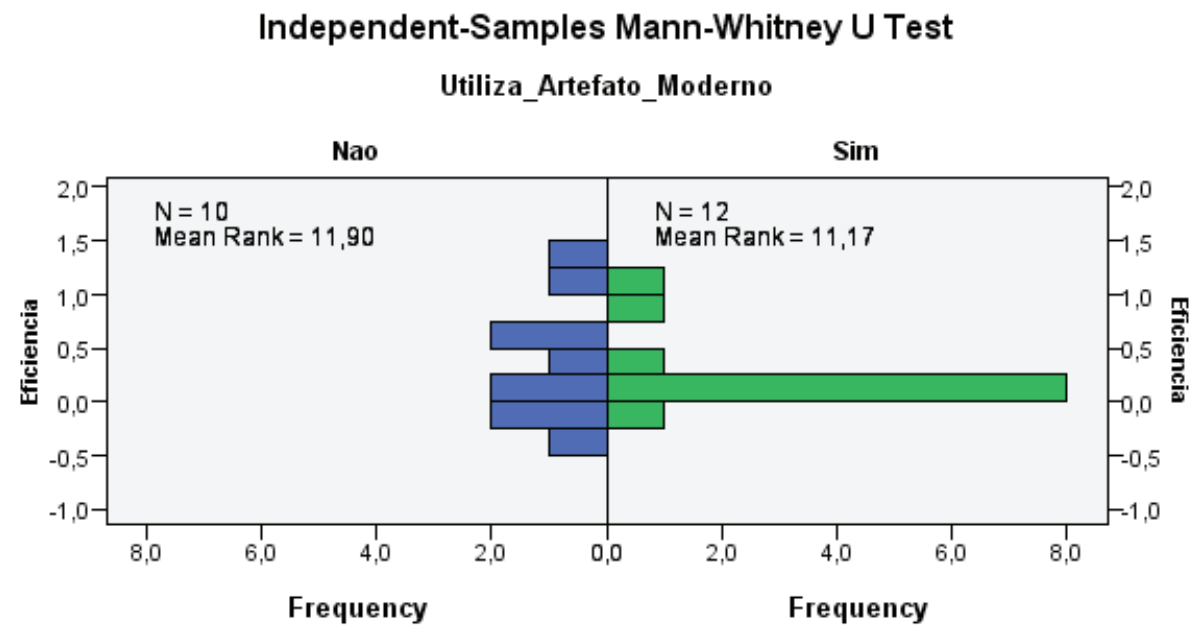

Figura 1. Teste de Eficiência, de Mann-Whitney, para amostras independentes 


\subsubsection{Indicador de rentabilidade}

Avaliando-se as variáveis artefatos modernos e indicador de rentabilidade, identificou-se que o resultado obtido para o valor-p foi superior ao nível de significância $(0,2030>0,05 \mathrm{com} U=79,5)$, indicando, portanto, não haver diferenças expressivas entre os valores do indicador de rentabilidade e as empresas que utilizam ou não artefatos modernos (Figura 2).

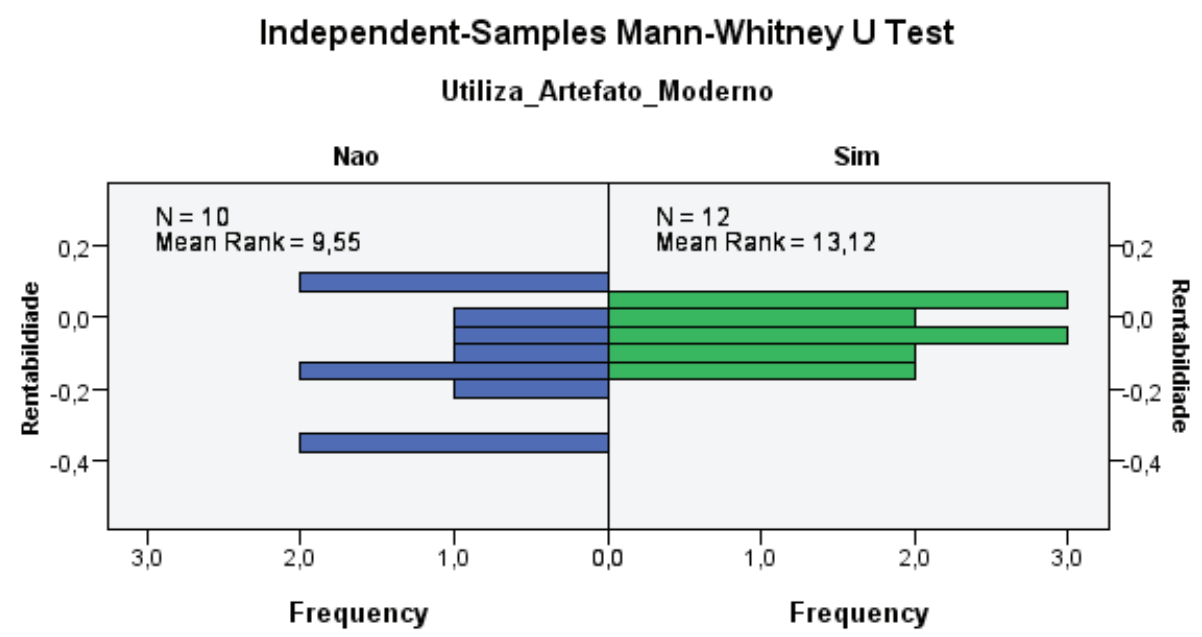

Figura 2. Teste de Rentabilidade, de Mann-Whitney, para amostras independentes

\subsubsection{Indicador de desempenho global de continuidade (DGC)}

Ao se aplicar o teste estatístico às variáveis artefatos modernos e DGC, evidenciou-se um valor-p superior ao nível de significância $(0,8212>0,05 \mathrm{com} U=63,5)$, deduzindo-se, desta forma, não haver diferenças relevantes entre os valores do indicador DGC e as empresas que utilizam ou não artefatos modernos (Figura 3).

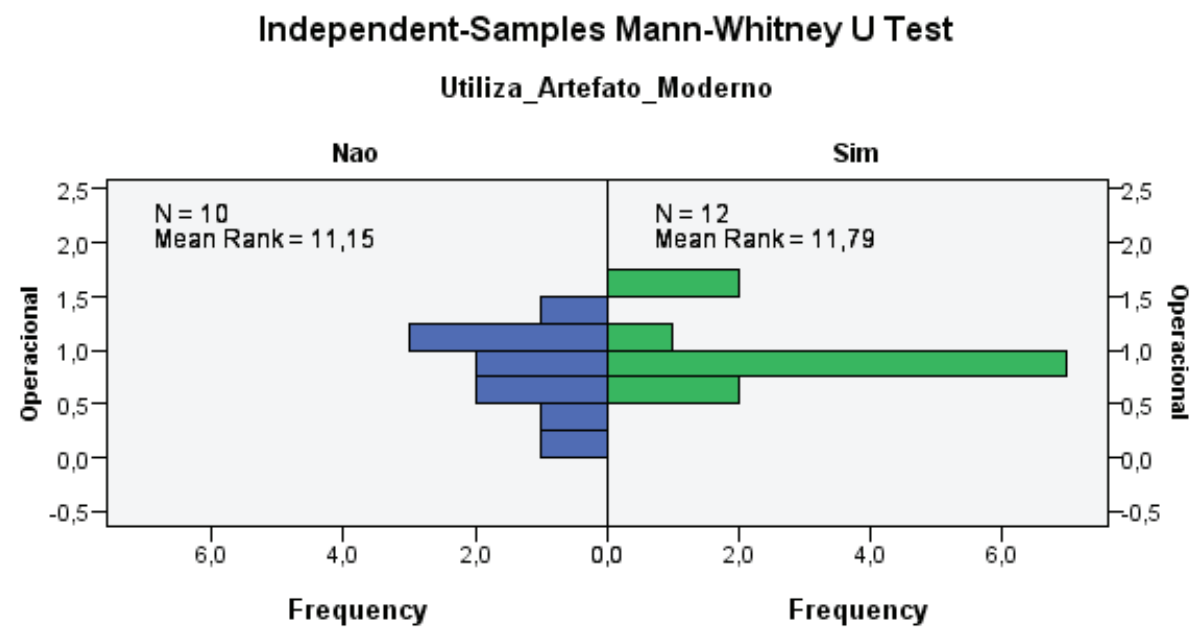

Figura 3. Teste de Operacionalidade, de Mann-Whitney, para amostras independentes (DGC) 
Os resultados desse item demonstram que a utilização de artefatos modernos não implica melhor desempenho econômico-financeiro, convergindo com os resultados encontrados por Reis e Teixeira (2013), segundo os quais não há relação entre a utilização de artefatos modernos e o desempenho financeiro diferenciado, ou seja, o grupo classificado como tradicional apresentou as mesmas médias de desempenho do grupo classificado como moderno. Por outro lado, tal resultado, os resultados aqui apresentados divergem daqueles encontrados na pesquisa de Soutes e Guerreiro (2007) em que as empresas brasileiras constantes na amostra estudada utilizavam artefatos classificados como modernos e apresentaram desempenho financeiro diferenciado.

Nesse sentido, com base na descrição dos indicadores de desempenho descritos na Metodologia, pode-se argumentar que a necessidade de enquadramento em limites regulatórios referentes ao desempenho pode ser um fator limitante à adoção ou incorporação dos artefatos. As atividades de controle no dia a dia, nesse sentido, podem tornar a busca pelo aperfeiçoamento gerencial via artefatos modernos um aspecto não prioritário, sendo a própria medida regulatória o "norteador" dos esforços gerenciais, ou ainda a busca pelo equilíbrio entre os diferentes indicadores, o principal objetivo a ser atingido. Assim, supõe-se que ferramentas mais personalizadas sejam utilizadas.

\subsection{Utilização de artefatos modernos e qualidade percebida}

Para se averiguar a hipótese de que a utilização de artefatos modernos da contabilidade implicaria em uma melhor percepção do consumidor quanto à qualidade dos serviços prestados pelas concessionárias (H3), adotou-se o teste de Mann-Whitney. O resultado do teste estatístico evidenciado na Figura 4 comprova que não há diferenças significativas entre os valores dos índices de satisfação dos consumidores e a utilização de artefatos modernos, visto que o valor-p foi superior ao nível de significância $(0,0692$ > 0,05 com $U=32$ ).

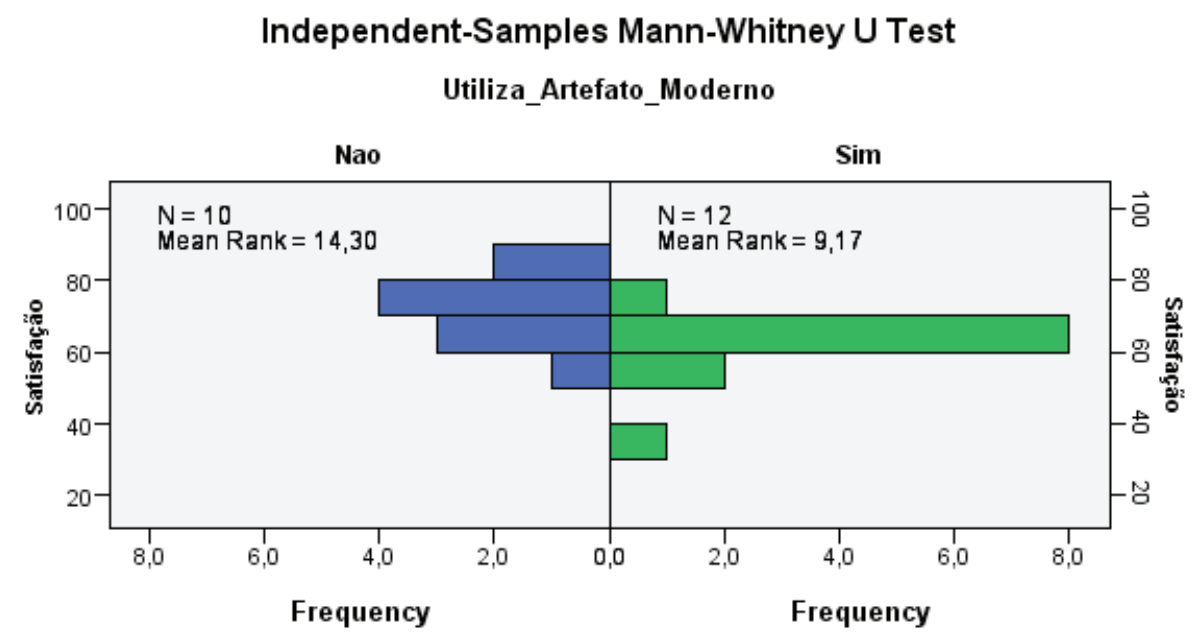

Figura 4. Teste de Mann-Whitney para amostras independentes (satisfação do consumidor)

Tendo em vista tais considerações e os resultados obtidos, pode-se argumentar que, apesar de o uso de artefatos modernos implicarem melhor embasamento para decisões relativas à redução de custos operacionais e geração de valor para o cliente final por meio das operações, o seu uso no âmbito das empresas pesquisadas não se mostra preponderante no sentido de se fazer cumprir os padrões regulatórios de qualidade. 
Por outro lado, cabe discutir alguns dos indicadores: em grande parte do País, não há como o consumidor trocar de fornecedor, o que acaba por distorcer a variável fidelidade (intenção de troca). Além disso, satisfação global preconiza conhecimento ou discernimento por parte do consumidor acerca do potencial de evolução das operações e serviços da empresa, o que pode levar também a distorções nas avaliações. Assim sendo, indicadores de qualidade podem estar dissociados daquilo que os artefatos modernos podem prover em termos de subsídio para estratégias de geração de valor para os consumidores.

Daí, especula-se que o foco da gestão das empresas, como um todo, esteja mais voltado ao atendimento às regulações do setor, as quais, não necessariamente, refletem as condições ou atributos de valor para usuários de energia, o que caracteriza o Governo e as agências reguladoras como stakeholders prioritários.

\subsection{Análises complementares}

Como complemento à análise das variáveis, adotou-se o teste de correlação de Kendall $(\tau)$. O Tau de Kendall é um coeficiente de correlação não-paramétrico, similar ao coeficiente de correlação de Spearman, porém, empregado quando se tem um conjunto pequeno de dados e um número elevado de postos empatados (Field, 2009). Mede-se com este coeficiente a associação entre duas variáveis no nível ordinal e o seu valor varia entre +1 e -1 , podendo-se determinar a direção, seja ela positiva ou negativa, bem como a intensidade dessa relação (Malhotra, 2012). Assim, tem-se H0: $\tau=0$, quando não existe correlação entre as duas variáveis e $\mathrm{H1}: \tau \neq 0$, quando há correlação entre as duas variáveis. Se o valor-p estiver abaixo de um dado nível de significância $($ valor- $p<0,05)$, rejeita-se a hipótese nula, para aquele nível de significância. Na Tabela 6, verifica-se a hipótese aceita, a intensidade da associação e a direção do relacionamento.

Tabela 6

\section{Teste de correlação de Kendall}

\begin{tabular}{|c|c|c|c|c|}
\hline Variável & Variável & Kendall $\tau$ & Valor-p & Hipótese \\
\hline Eficiência & Nota Artefato Moderno & 0,0485 & 0,7556 & $\mathrm{HO}$ \\
\hline Eficiência & Nota Tradicional & 0,0493 & 0,7545 & $\mathrm{HO}$ \\
\hline Rentabilidade & Nota Artefato Moderno & 0,0749 & 0,6305 & $\mathrm{HO}$ \\
\hline Rentabilidade & Nota Tradicional & 0,0493 & 0,7546 & $\mathrm{HO}$ \\
\hline Rentabilidade & Eficiência & $-0,6711$ & $<, 0001$ * & $\mathrm{H} 1$ \\
\hline DGC & Nota Artefato Moderno & 0,1363 & 0,3806 & $\mathrm{HO}$ \\
\hline DGC & Nota Tradicional & 0,1522 & 0,3342 & $\mathrm{HO}$ \\
\hline DGC & Eficiência & 0,3764 & 0,0151 * & $\mathrm{H} 1$ \\
\hline DGC & Rentabilidade & $-0,2101$ & 0,1750 & $\mathrm{HO}$ \\
\hline Satisfação & Nota Artefato Moderno & $-0,2276$ & 0,1417 & $\mathrm{HO}$ \\
\hline Satisfação & Nota Tradicional & $-0,2585$ & 0,0997 & $\mathrm{HO}$ \\
\hline Satisfação & Eficiência & $-0,3486$ & $0,0239 *$ & $\mathrm{H} 1$ \\
\hline Satisfação & Rentabilidade & 0,1482 & 0,3371 & $\mathrm{HO}$ \\
\hline Satisfação & DGC & $-0,2130$ & 0,1667 & $\mathrm{HO}$ \\
\hline Qtde. Artefatos Modernos & Eficiência & 0,0774 & 0,7322 & $\mathrm{HO}$ \\
\hline Qtde. Artefatos Modernos & Rentabilidade & 0,1505 & 0,5037 & $\mathrm{HO}$ \\
\hline Qtde. Artefatos Modernos & DGC & 0,3568 & 0,1031 & $\mathrm{HO}$ \\
\hline
\end{tabular}

Nota: (*) Teste significativo ao nível de 5\%. 
De acordo com os resultados evidenciados, quanto menor o valor do indicador DGC, menor o valor do indicador eficiência $(\tau=0,3764$, valor- $p=0,0151)$; quanto maior o valor do indicador de rentabilidade, menor o valor do indicador de eficiência $(\tau=-0,6711$, valor- $p<0,001)$ e, quanto menor $o$ valor do indicador eficiência, maior o indicador de satisfação $(\tau=-0,3486$, valor- $p=0,0239)$. Não há correlação entre o número de artefatos modernos utilizados e o desempenho econômico-financeiro das concessionárias (valor-p $>0,05$ ). Conclui-se que os indicadores DGC e rentabilidade estão correlacionados, predominantemente, com o indicador de eficiência, sabendo-se que o indicador de eficiência é a única variável correlacionada com satisfação dos clientes. Os dados sugerem que a eficiência das empresas pode ser impactada em virtude de um satisfatório desempenho financeiro que, por sua vez, pode garantir maior satisfação do consumidor por meio do direcionamento dos recursos a ações de qualidade.

De acordo com a Aneel (2016a), não raramente, as dificuldades relacionadas às finanças das distribuidoras decorrem principalmente da baixa eficiência na gestão dos custos operacionais, mais do que do volume de dívida das empresas.

\section{Conclusão}

Esta pesquisa teve como objetivo analisar a relação entre a utilização dos artefatos modernos da contabilidade e o porte, o desempenho econômico-financeiro e a qualidade dos serviços prestados por uma amostra de empresas brasileiras concessionárias de distribuição de energia elétrica.

Para caracterizar os artefatos da contabilidade utilizados pelas empresas, a análise dos dados foi segregada por estágios, considerando-se uma maior frequência em torno dos artefatos tradicionais. $\mathrm{O}$ planejamento estratégico está presente em 19 das 22 empresas; o orçamento, em 20 delas; o benchmarking, em 18 e, o Balanced Scorecard, em 19 empresas, sendo estes os artefatos mais utilizados. Em contrapartida, o Kaizen, que abrange duas das empresas; o Gecon, duas e, o Just in Time, três delas, são os menos utilizados. De maneira geral, pode-se concluir que poucas empresas concessionárias apresentam o foco de sua contabilidade gerencial na geração de valor por meio do uso efetivo dos recursos a partir de direcionadores como valor para o consumidor, valor para o acionista e inovação organizacional (International Federation of Management Accountants, 1998; Soutes \& Guerreiro, 2007) e que mesmo em setores em que vigoram complexas condições regulatórias, a utilização de artefatos modernos que estejam alinhados a essas exigências não se mostra preponderante, conforme idealizado a priori.

Para se verificar a relação entre o porte das referidas empresas e a utilização de artefatos modernos da contabilidade gerencial, testou-se a hipótese H1 por meio do teste de Qui-Quadrado, comprovandose a existência de uma associação entre o porte das concessionárias e a utilização de artefatos modernos. Pode-se especular que, em setores marcados por intensa regulação, em especial no caso do setor elétrico, o crescimento organizacional, principalmente via fusões e aquisições, pode estar intimamente relacionado à utilização de recursos com foco na geração de valor, tanto para o consumidor quanto para acionistas. Dessa maneira, o emprego dos artefatos modernos se faz essencial. 
Quanto à existência de uma associação entre a utilização de artefatos modernos da contabilidade gerencial e o desempenho econômico-financeiro, hipótese $\mathrm{H} 2$, verificou-se, por meio do teste $\mathrm{U}$ de MannWhitney, a sua rejeição, isto é, não se pode afirmar que o uso de artefatos modernos da contabilidade gerencial tenha relação com o desempenho econômico-financeiro. A partir de uma comparação com estudos prévios, tal constatação obteve resultado convergente com a pesquisa realizada por Reis e Teixeira (2013), porém, divergente daquele apresentado por Soutes e Guerreiro (2007). Cabe ressaltar que esses autores se utilizam de uma amostra plural, com empresas de diferentes setores, diferentemente deste estudo que se utiliza de uma amostra de empresas com perfil específico. Dessa maneira, visando trazer maior visibilidade à relação entre o uso de artefatos e desempenho, sugerem-se maiores investigações acerca de influências institucionais aos direcionadores de custos operacionais dessas empresas, partindo-se da premissa de que onerações a partir dos marcos regulatórios não necessariamente requerem a sofisticação da função das práticas da contabilidade gerencial como apoio à tomada de decisão gerencial. Por outro lado, se o uso de artefatos modernos nesse contexto regulatório se faz imprescindível, pode-se argumentar que a adoção e a institucionalização dessas práticas nas empresas analisadas merecem um olhar mais detalhado. Nessa esfera de análise, as demandas relacionadas à especialização jurídica podem suplantar a necessidade de práticas da contabilidade gerencial mais alinhadas à geração de valor por parte da gestão.

Para se avaliar a relação entre a utilização de artefatos e o nível de qualidade dos serviços prestados pelas referidas empresas, aplicou-se a hipótese H3, segundo a qual o emprego de artefatos modernos corrobora para uma melhor percepção do consumidor quanto aos serviços prestados pelas concessionárias. O resultado decorrente do teste U de Mann-Whitney rejeitou tal hipótese, o que leva à conclusão de que não existem diferenças relevantes entre os valores do índice de satisfação e o uso de artefatos modernos. A ausência de uma relação entre o uso de artefatos modernos e a qualidade percebida pelos consumidores das empresas da amostra levam a crer que os indicadores de qualidade ou independem do uso de práticas da contabilidade gerencial mais voltadas à geração de valor, tendo-se ações de baixo custo como transparência como fator expressivo da qualidade percebida.

De acordo com a Tabela 5, adotando-se o teste de correlação de Kendall, pode-se concluir que não existe correlação entre a quantidade de artefatos com o desempenho econômico-financeiro das concessionárias. Porém, os indicadores DGC e Rentabilidade estão correlacionados, significativamente, com o indicador de Eficiência, o qual, por sua vez, está correlacionado, excepcionalmente, com a satisfação dos clientes. Assim, sugere-se posterior verificação causal entre eficiência das empresas e seu consequente desempenho financeiro, e a garantia de uma melhor percepção de qualidade de serviços por parte do consumidor.

Diante dessas considerações, ressalta-se que a principal contribuição deste trabalho é o fato de que os artefatos modernos ainda não são percebidos pela maioria das empresas investigadas como relevantes à geração de valor ao consumidor ou ao acionista, ou como útil subsídio gerencial às limitações regulatórias inerentes a um monopólio natural.

Apesar dos achados, algumas limitações relativas à pesquisa devem ser consideradas: $\mathrm{o}$ fato de se ter trabalhado com uma amostra não probabilística, o que significa que os resultados são válidos apenas para a amostra estudada e as inferências inerentes se restringem ao grupo em questão. A análise quantitativa envolveu apenas artefatos modernos. Dessa forma, recomenda-se cautela, no tocante à extrapolação dos achados da pesquisa e, também, quanto às comparações com outros estudos relativos ao uso de artefatos de contabilidade gerencial. 


\section{Referências}

Agência Nacional de Energia Elétrica(2016). Instituição de Indicadores Públicos de Sustentabilidade Econômico-Financeira. Nota Técnica No 111/2016 - SRD/ANEEL., Brasília (DF). pp. 1-46 Recuperado dehttps://www2.aneel.gov.br/aplicacoes/consulta_publica/documentos/Nota_ Tecnica_2016_111.pdf

Agência Nacional de Energia Elétrica.(2013). Indicador de Desempenho Global de Continuidade de 2012 e Variação Anual dos Indicadores DEC e FEC de 2012. Recuperado de http://www2.aneel.gov.br/ arquivos/PDF/Nota_Tecnica_0038_Ranking.pdf

Agência Nacional de Energia Elétrica. (2016). ANEEL Divulga Ranking de Qualidade das Distribuidoras de Energia. Recuperado de http://www.aneel.gov.br/sala-de-imprensa-exibicao-2/-/asset_ publisher/zWQREz8EV 1Z6/content/aneel-divulga-rankin-de-qualidade-das-distribuidoras-deenergia/656877

Agência Nacional de Energia Elétrica. (2017). Índice ANEEL de Satisfação do Consumidor (IASC). Recuperado de http://www.aneel.gov.br/indice-aneel-satisfacao-consumidor

Agência Nacional de Energia Elétrica. (s.d.). Central de Informações Econômico-Financeiras. Recuperado de http://www.aneel.gov.br/central-de-informacoes-economico-financeiras

Associação Brasileira de Distribuidores de Energia Elétrica. (s.d.). A Distribuição de Energia. Recuperado de http://www.abradee.com.br/setor-de-distribuicao/a-distribuicao-de-energia

Atkinson, A. A., Kaplan, R. S., Matsumura, E. M., \& Young, S. M. (2015). Contabilidade gerencial: Informação para Tomada de Decisão e Execução da Estratégia. $4^{a}$ ed. São Paulo: Atlas.

Augusto, M. G., Lisboa, J. V., \& Yasin, M. M. (2014). Organizational Performance and Innovation in the Context of a Total Quality Management Philosophy: An Empirical Investigation. Total Quality Management \& Business Excellence, 25, pp.1141-1155. doi:10.1080/14783363.2014.886372

Bjoornenak, T., \& Olson, O. (1999). Unbundling Management Accounting Innovations. Management Accounting Research, 10(4), pp, 325-338. doi:10.1006/mare.1999.0110

Bruni, A. L. (2012). SPSS: Guia Prático para Pesquisadores. São Paulo: Atlas.

Cochran, W. G. (2007). Sampling Techniques. New York: Wiley.

Crepaldi, S. A., \& Crepaldi, G. S. (2014). Contabilidade gerencial: Teoria e Prática. São Paulo: Atlas.

Curwin, J., \& Slater, R. (2008). Quantitative Methods for Business Decisions. London: Thomson.

Espejo, M. M., Portulhak, H., \& Martins, D. B. (2015). Práticas de Controle Gerencial em Hospitais Universitários Federais. Gestão e Regionalidade, 31(92), pp.39-52. doi:10.13037/gr.vol31n92.2421

Field, A. (2009). Descobrindo a Estatística Usando o SPSS. 2a ed. Porto Alegre: Artmed.

Figueiredo, L. V. (2016). Lições de Direito Econômico. 9a ed. Rio de Janeiro: Forense.

Fonseca, J., \& Martins, G. A. (2012). Curso de Estatística. São Paulo: Atlas.

Freund, J. E. (2006). Estatística Aplicada: Economia, administração e contabilidade. $11^{a} \mathrm{ed}$. Porto Alegre: Bookman.

Gonzaga, R. P., Luz, A. T., Guimarães, T. N., \& Valerio Junior, V. B. (2010). Associação entre Práticas de Contabilidade gerencial e Tamanho das Empresas: Um Estudo Empírico. IV Congresso ANPCONT, pp. 1-16. Recuperado de http://www.fucape.br/_public/producao_cientifica/2/Rosimeire\%20 Pimentel.pdf 
Grande, J. F., \& Beuren, I. M. (2011). Mudanças nas Práticas de Contabilidade gerencial de Empresas. julho/setembro 2011 Revista de Administração FACES Journal, 11(3), pp. 84-104. Recuperado de http://www.fumec.br/revistas/facesp/article/view/636

Guerreiro, R., \& Soutes, D. O. (2013). Time-Based Management Practices: A Study of Brazilian Companies. Revista Contabilidade \& Finanças, 24(63), pp. 181-194. doi:10.1590/S1519-70772013000300002

Guerreiro, R., Cornachione Júnior, E. B., \& Soutes, D. O. (2011). Do Companies who Stand out for Information Quality for External Users also Stand out for the Use of Modern Management Accounting Artifacts? Revista Contabilidade \& Finanças, 22(55), pp. 88-113. doi:10.1590/S151970772011000100006

Hair Jr., J. F., Black, W. C., Babin, B. J., Anderson, R. E., \& Tatham, R. L. (2009). Análise Multivariada de Dados.6 $6^{\mathrm{a}}$ ed. Porto Alegre: Bookman.

International Federation of Accountants,. International Management Accounting Practice Statement (1998), Management Accounting Concepts. Financial and Management Accounting Committee, New York.

Ittner, C. D., \& Larcker, D. F. (1995). Total Quality Managemetn and The Choice of Information and Reward Systems. Journal of Accounting Research, (33), pp1-34. doi:10.2307/2491371

Jansen, E. P. (2018). Bridging the Gap between Theory and Practice in Management Accounting: Reviewing the Literature to Shape Interventions. Accounting, Auditing \& Accountability Journal, 31(5), pp. 1486-1509. doi:10.1108/AAAJ-10-2015-2261

Junqueira, E., Dutra, E. V., Zanquetto Filho, H., \& Gonzaga, R. P. (2016). The Effect of Strategic Choices and Management Control Systems on Organizational Performance. Revista Contabilidade \& Finanças, 27(72), pp. 334-348. doi:10.1590/1808-057x201601890

Klein, L., \& Almeida, L. B. (2017). A Influência dos Fatores Contingenciais na Adoção de Práticas de Contabilidade gerencial nas Indústrias Paranaenses. Revista Universo Contábil, 13(3), pp. 90119. Recuperado de https://proxy.furb.br/ojs/index.php/universocontabil/article/view/5424/pdf doi:10.4270/ruc. 2017320

Leite, E. G., Diehl, C. A., \& Manvailer, R. H. (2015). Práticas de Controladoria, Desempenho e Fatores Contingenciais: Um Estudo em Empresas Atuantes no Brasil. Revista Universo Contábil, 11(2), pp. 85-107. Recuperado de https://proxy.furb.br/ojs/index.php/universocontabil/article/ view/4373/3029 doi:10.4270/ruc.2015213

Lunkes, R. J., Costa, C. H., Bortoluzzi, D. A., \& Rosa, F. S. (2018). Study on the Adoption of Management Accounting Practices in Hotel Companies in Florianópolis, SC, Brazil. Revista Turismo em Análise, 29(2), pp. 216-235. doi:10.11606/issn.1984-4868.v29i2p216-235

Malhotra, N. (2012). Pesquisa de Marketing: Uma Orientação Aplicada. Porto Alegre: Bookman.

Michel, M. H. (2009). Metodologia e Pesquisa Científica em Ciências Sociais. São Paulo: Atlas.

Morais, O. d., Coelho, A. C., \& Holanda, A. P. (2014). Artefatos de Contabilidade gerencial e Maximização do Valor em Firmas Brasileiras. Contabilidade e Controladoria, 6(2), pp. 128-146. Recuperado de https://revistas.ufpr.br/rcc/article/view/35409/23562 doi:10.5380/rcc.v6i2.35409

Morettin, P. A. (2009). Estatística Básica $6^{a}$ ed.. São Paulo: Saraiva.

Oliveira, M. C., C, O. B., Daher, W. M., \& Ribeiro, M. S. (2006). Análise Segundo o Modelo de Hopkins das Ações de Responsabilidade Social Empresarial Evidenciadas nas Demonstrações Contábeis e Balanços Sociais: O Caso das Distribuidoras de Energia do Grupo Brasileiro Neoenergia. Brazilian Business Review, 3(1), pp. 32-45. Doi: http://dx.doi.org/10.15728/bbr.2006.3.1.3 
Padoveze, C. L. (2010). Contabilidade gerencial: Um Enfoque em Sistema de Informação Contábil. São Paulo: Atlas.

Paulo, A. S., \& Cintra, Y. C. (2018). O Uso de Artefatos de Contabilidade gerencial no Ciclo de Vida de Empresas do Setor Têxtil: O Caso ACR Fashion. Revista de Contabilidade do Mestrado em Ciências Contábeis da UERJ, 23(1), pp. 1-19. Recuperado de https://www.e-publicacoes.uerj.br/index.php/ rcmccuerj/article/view/39297 DOI: https://doi.org/10.12979/rcm

Pessanha, J. F., Souza, R. C., \& Laurencel, L. C. (2007). Um Modelo de Análise Envoltória de Dados para o Estabelecimento de Metas de Continuidade do Fornecimento de Energia Elétrica. Pesquisa Operacional, 27(1), pp. 51-83. Recuperado de http://www.scielo.br/scielo.php?script=sci_arttext\&pid=S0101$74382007000100004 \& \operatorname{lng}=$ pt\&nrm=iso\&tlng=pt doi:10.1590/S0101-74382007000100004

Reis, A. M., \& Teixeira, A. J. (2013). Use of Management Accounting Artifacts in Agricultural Cooperatives from Minas Gerais and its Relation with Size and Financial Performance. Revista de Educação e Pesquisa em Contabilidade, 7(4), pp. 342-358. Recuperado de http://www.repec.org.br > download

Reis, R. M., Teixeira, A. C., \& Pires, M. A. (2007). Os Benefícios da Privatização: Evidência no Setor Elétrico Brasileiro. Revista de Contabilidade e Organizações, 1, pp. 56-70. Recuperado de http:// www.revistas.usp.br/rco/article/view/34697 doi:10.11606/rco.v1i1.34697

Rufino, R. FGV Energia (2015). Energia em Foco: Estratégias e Desafios para o Futuro. Cenário e Perspectivas para o Setor Elétrico Brasileiro. Recuperado de https://fgvenergia.fgv.br/sites/fgvenergia.fgv.br/files/ apresentacao_cenario_perspectivas_do_setor_ee_dr_romeu_27_08_15.pdf

Russo, P. T., Parisi, C., \& Pereira, C. A. (2016). Evidências das Forças Causais Críticas dos Processos de Institucionalização e Desinstitucionalização em Artefatos da Contabilidade. Revista Contemporânea de Contabilidade, 13(30), pp. 3-33. doi:10.5007/2175-8069.2016v13n30p3

Sedevich-Fons, L. (2018). Linking Strategic Management Accounting and Quality Management Systems. Business Process Management Journal, 24(6), pp. 1302-1320. doi:10.1108/BPMJ-02-2018-0038

Silvestre, B. H., Matos, S., \& Figueira, L. A. (2010). Privatização: Bom ou Ruim? Lições do Setor de Distribuição de Energia Elétrica do Nordeste Brasileiro. Revista de Administração de Empresas, 50(1), pp. 94-111. doi:10.1590/S0034-75902010000100008

Soutes, D. O. (2006). Uma Investigação do Uso de Artefatos da Contabilidade gerencial por Empresas Brasileiras. Dissertação de Mestrado em Ciências Contábeis, Universidade de São Paulo, Departamento de Contabilidade e Atuária, São Paulo (SP). DOI:10.11606/D.12.2006.tde-12122006-102212

Soutes, D. O., \& Guerreiro, R. (2007, setembro). Uma Investigação do Uso de Artefatos da Contabilidade gerencial por Empresas Brasileiras. Anais do XXI Encontro da ANPAD, Rio de Janeiro, RJ. Recuperado de http://www.anpad.org.br/admin/pdf/CON-B1934.pdf

Sulaiman, M., Ahmad, N. N., \& Alwi, N. (2004). Management Accounting Practices in Selected Asian Countries: A Review of the Literature. Managerial Auditing Journal, 4(19), pp. 493-508. doi:10.1108/02686900410530501

Teixeira, A. J., Gonzaga, R. P., Santos, A. V., \& Nossa, V. A. (2011). A Utilização de Ferramentas de Contabilidade gerencial nas Empresas do Estado do Espírito Santo. Brazilian Business Review, 8(3), pp. 108-127. Recuperado de http://legado.fucape.br/_public/producao_cientifica/2/BBR\%20-\%20ARIDELMO.pdf http://legado.fucape.br/_public/producao_cientifica/2/BBR\%20-\%20ARIDELMO.pdf 